\title{
ИСТОРИЯ АСАМИ - ИСТОРИЯ РАСПРОСТРАНЕНИЯ МЕТОДА ИЛИЗАРОВА
}

\author{
Шевцов В.И. \\ Национальный медицинский исследовательский центр травматологии и ортопедии \\ МЗ РФ. чл-корр. РАН, докт. мед наук, профессор, почетный профессор НМИЦ ТО МЗ РФ)
}

Введение. В 1952 г. врач Г.А. Илизаров создал оригинальный аппарат собственной конструкции, что подтверждается полученным им авторским свидетельством № 98471. В 1955 он сообщил об удлинении конечности на 12.5 см. Проведя экспериментальные исследования Г.А. Илизаров разработал малоинвазивные технологии удлинения конечностей и регуляции роста, коррекции деформаций, возмещения дефектов длинных костей и др. Цель исследования. Представить историю создания ассоциации по изучению аппарата и метода Илизарова (АСАМИ). Материал. В процессе подготовки выступления было проведено изучение 50 единиц архивного хранения Российского научного центра «Восстановительная травматология и ортопедия» им. Г.А. Илизарова, а также данные личного архива и фототеки автора. Обсуждение и результаты. Достижения Г.А. Илизарова привлекли внимание зарубежных специалистов. С целью быстрого освоения нового метода лечения травматолого-ортопедических больных, итальянский проф. А. Б-Майокки создал в Италии и в соседних с нею странах, ассоциации по изучению аппарата и метода Илизарова (АСАМИ). В последующие годы АСАМИ были созданы в 56 странах.

Introduction. In 1952, the doctor G.A. Ilizarov created an original apparatus of his own design, which is confirmed by the author's certificate No. 98471 received by him. In 1955, he reported on limb elongation by $12.5 \mathrm{~cm}$. After conducting experimental studies, G.A. Ilizarov developed minimally invasive technologies for limb elongation and regulation of growth, correction of deformations, replacement of defects in long bones, etc. The purpose of the study. Produce the history of the Association for the Study of the Apparatus and Method of Ilizarov (ASAMI). Material. In the process of preparing the speech, 50 units of archival storage of the G.A. Ilizarov Russian Scientific Center "Restorative Traumatology and Orthopedics," as well as data from the author's personal archive and photo library were studied. Discussion and results. The achievements of G.A. Ilizarov attracted the attention of foreign specialists. In order to quickly master a new method of treating traumatic and orthopedic patients, Italian prof. A. B-Mayokki created in Italy and its neighboring countries, associations for the study of the apparatus and method of Ilizarov (ASAMI). In subsequent years, ASAMI was established in 56 countries.

Ключевые слова: АСАМИ, метод Илизарова, распространение.

Key words: ASAMI, Ilizarov method, distribution.

28 декабря 2021 г. в г. Дакка (Бангладеш) состоялась 9 конференция посвященная 10 годовщине создания АСАМИ - Бангладеш. Автор сообщения принимал в ней участие. Ниже приводится текст выступления.

Уважаемые коллеги!! Приветствую и поздравляю всех участников девятой конференции, посвященной 10 летнему юбилею АСАМИ Бангладеш. 


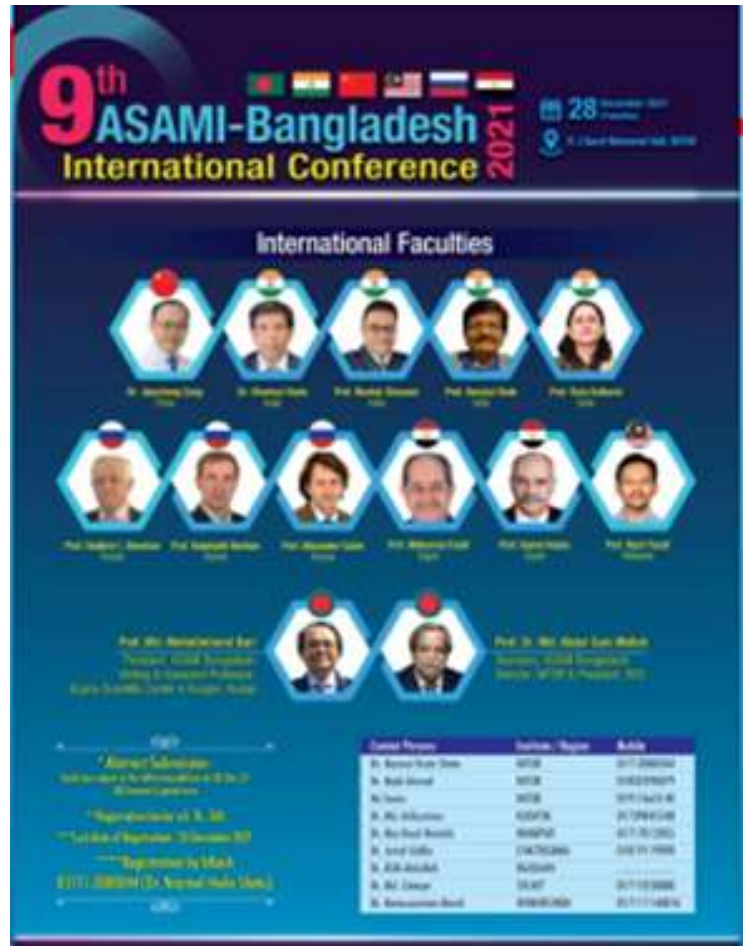

Рис. 1. Программа и основные докладчики на конференциии АСАМИ Бангаледи.

2021 год в России проходил под флагом 100 -летия со дня рождения проф. Г.А. Илизарова, 70 лет методу Илизарова и 50 лет Центру Илизарова. 50 лет отмечалось 8 декабря прошлого (2021 г) года.

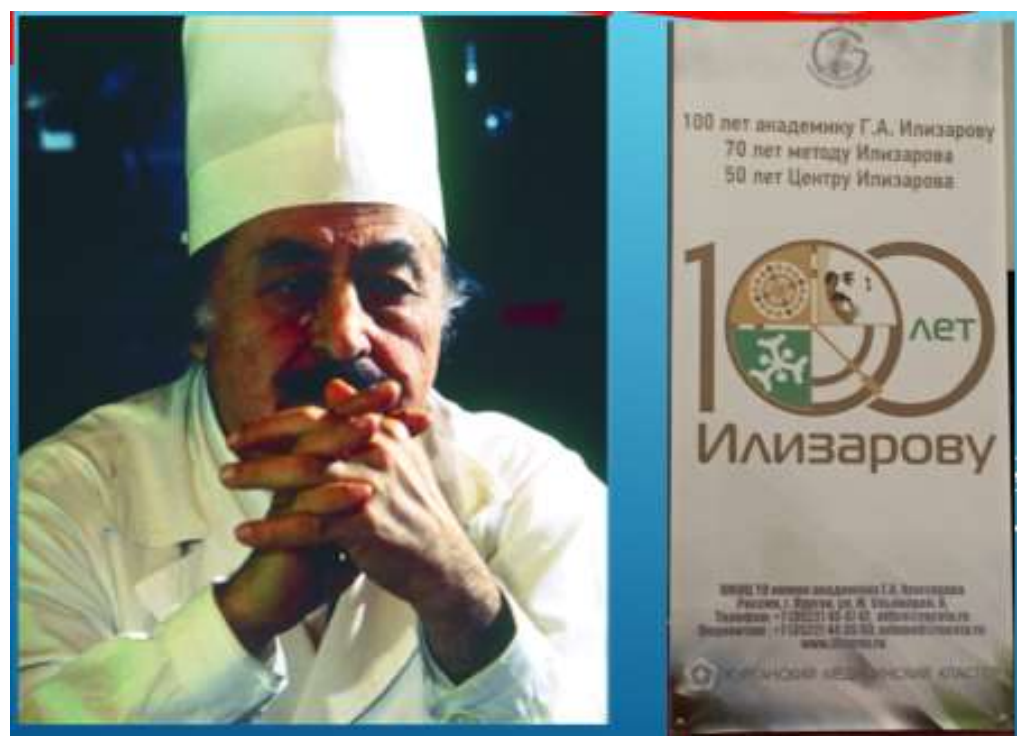

Рис. 2. Фото плаката подготовленного к 100 -летию со дня рождения Г.А. Илизарова.

Следует сказать, что достижения проф. Г.А. Илизарова стоят в одном ряду с открытием рентгеновского и ядерного излучения, периодической таблицей химических элементов Д.И. Менделеева и др.

Трудно не согласиться с мнением Хаслера К.К и Крига К., которые заявляют: «История хирургического удлинения костей включает в себя 100 захватывающих лет борьбы, развития и непрерывного обучения. Первоначальная стратегия быстрого или постепенного перемещения костных отломков длилась почти полвека, пока Илизаров не доказал преимущества биологических остеотомий и постепенного удлинения с медленным темпом (1 мм / день) при суточном ритме $4 \times 0,25$ мм $^{1} \gg$.

Как только достижения Г.А. Илизарова стали известны за пределами России, появились активные сторонники его метода, которые способствовали распространению и внедрению в разных странах мира учения Г.А. Илизарова. Как это происходило я хочу кратко рассказать в своем сообщении. Весной 1969 года из порта 
Сафи, Марокко, вышла папирусная лодка «Ра» под командованием норвежского путеше-ственника Тура Хейердала.

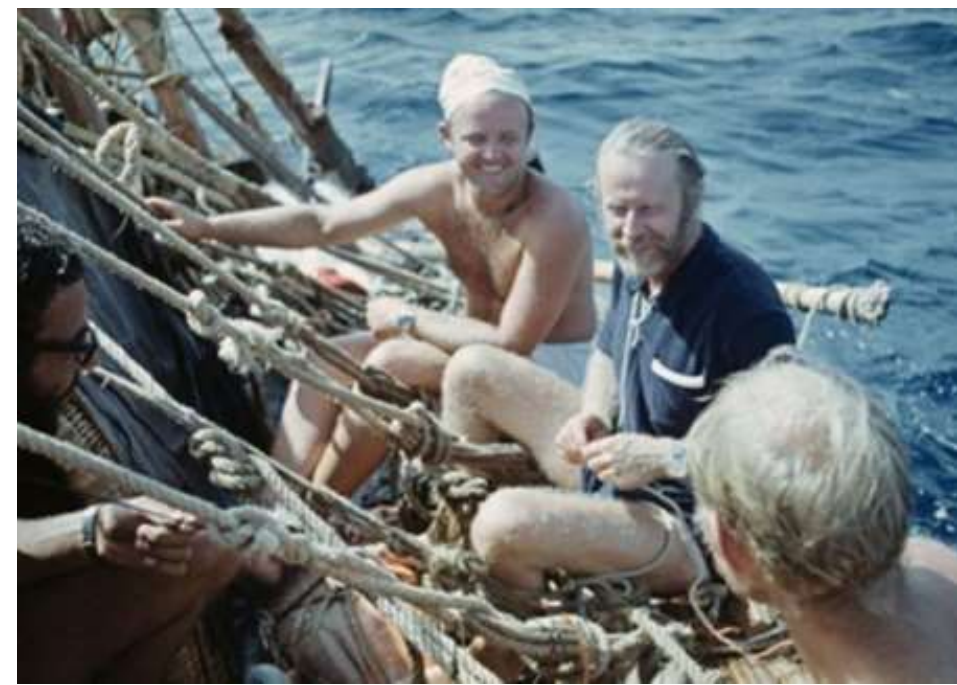

Рис. 3. Ю. Сенкевич и Т. Хейердал во время путешествия на папирусной лодке «Ра»

Перед экипажем, состоящим из 7 человек, в числе которых был наш соотечественник врач Юрий Сенкевич, стояла задача переплыть Атлантический океан.

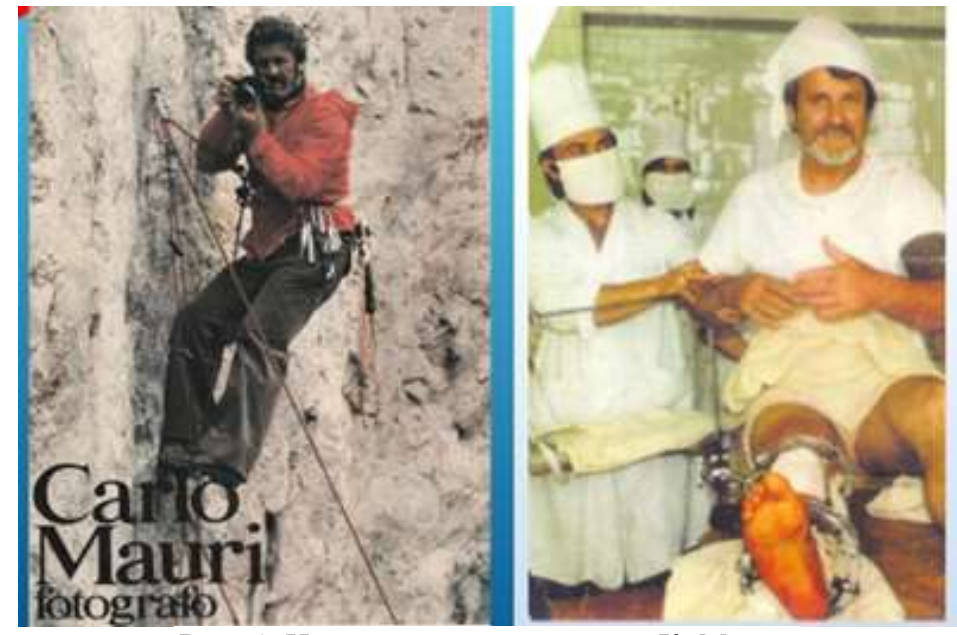

Рис. 4. Итальянский альпинист К. Маури.

В составе экипажа был итальянский альпинист Карло Маури. Во время одного из восхождений в горы К. Маури получил перелом большеберцовой кости, в результате развилось укорочение голени и деформация стопы. Ю. Сенкевич рассказал ему об Г.А. Илизарове и после завершения путешествия организовал приезд Карло Маури в Курган, где ему проведено было необходимое лечение. К. Маури очень понравилось в Кургане и после возвращения на родину он стал активным пропагандистом Г.А. Илизарова и его метода лечения.

На страницы зарубежной печати попала информация о накопленных новых знаниях по регенерации костей и других тканей в условиях компрессионного и дистракционного остеосинтеза, о разработанных новых малотравматичных

1 (K.K. Hasler, R.Krieg. Modren concepts of leg lengthening. J. Paed. Orthop. 2012 June; 6(2):89-104. DOI:10.1007/s11832-012-0391-5.Epub2021.)

И высокоэффективных методах лечения, возможностях удлинения конечностей на необходимую величину и регуляции роста, достижения консолидации переломов костей в короткие сроки. И вот итальянский журнал «Stampa Medica» в 1982 году обратился через Агентство печати «Новости» к профессору Г. А. Илизарову с просьбой кратко рассказать о его творчестве. Газета попросила его представить материалы, подтверждающие результаты лечения. 
Опубликованная информациия на страницах журнала заинте-ресовала итальянского профессора Антонио Бьянки - Майокки.

И в 1983 г. он организовал группу итальянских врачей в составе М. Катаньи, А. Вилла, С. Бенедетти для поездки в г. Курган. За время пребывания в нашем центре были отсняты тысячи метров фото- и видеодокументов.

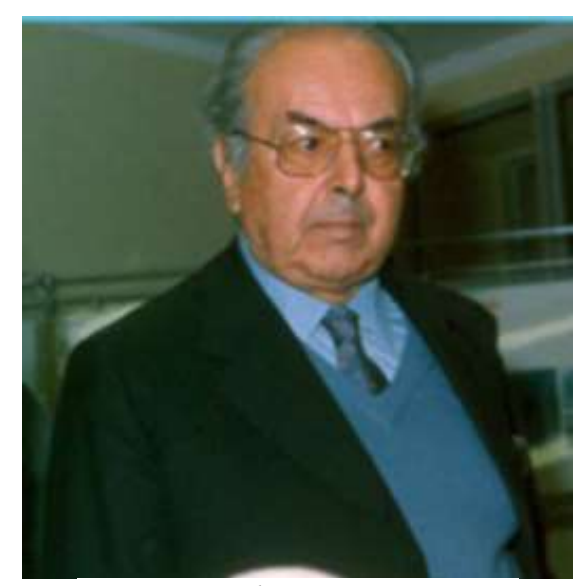

Рис. 5. Проф. А. Б- Майокки.

В этом же году А. Б- Майокки пригласил Г.А. Илизарова на конференцию, проходившую в г. Лекко. Конечно же Г.А. Илизаров потребовал, чтобы ему для каждого доклада дали не менее полутора часов. Итальянцы в конечном счете согласились с его требованиями. Г.А. Илизаров прочитал 4 доклада, каждый продолжительностью по 2 часа. При демонстрации случаев, с блестящими результатами лечения, сидящие в зале вскакивали с мест, раздавались бурные аплодисменты, пере-ходящие в овации.

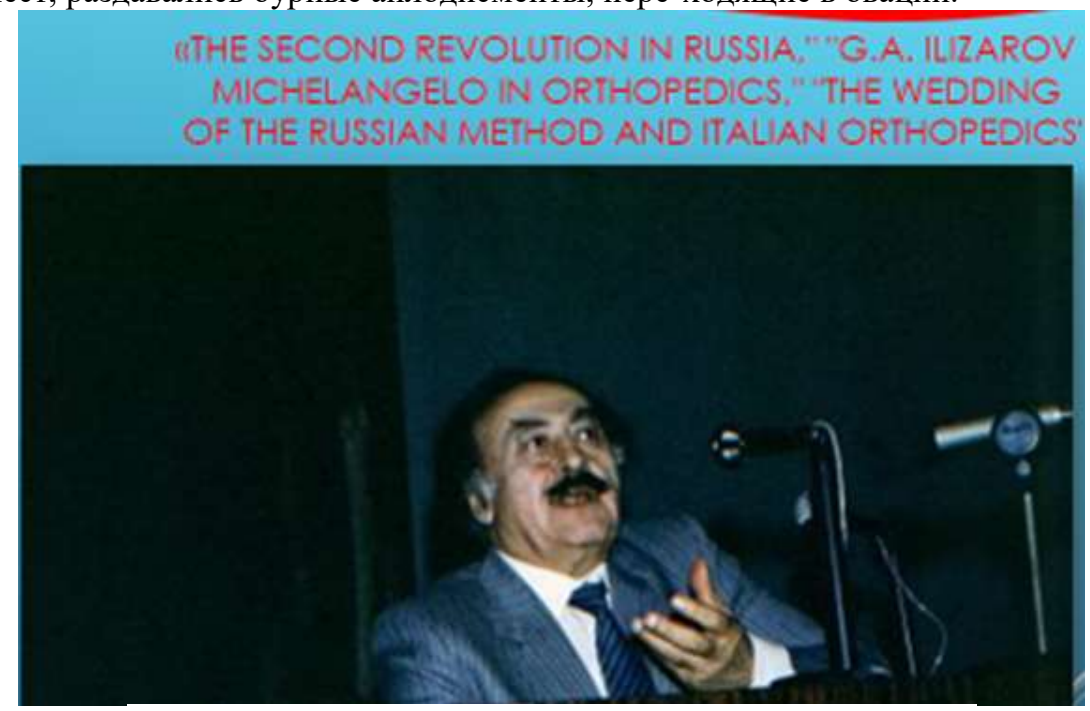

Рис. 6. Фото проф. Г.А. Илизарова из итальянских газет

Итальянцы очень восторженно принимали сообщения проф. Г.А. Илизарова. Все газеты были заполнены информа-цией о достижениях русского врача под заголовками: «Новая революция в России», «Свадьба российского метода и итальянской ортопедии», а Г.А. Илизаров это -«Микельанжело в ортопедии»,

При очередном посещении Италии в 1984 г. Б. Майокки сообщил проф. Г.А. Илизарову о том, что он решил создать ассоциацию по изучению аппарата и метода Илизарова, которую он назвал АСАМИ. Б.- Майокки был очень активный коммерсант. И в ближайшие годы он организовал АСАМИ во всех соседних с Италией странах: Франции, Бельгии, Германии и др. Затем были организованы АСАМИ Бразилии и Мексики.

Задача АСАМИ изучение, освоение и внедрение метода Г.А. Илизарова в практику лечебных учреждений Италии и других стран Европы. Первым президентом АСАМИ был утвержден проф. Р. Катанео.

Одновременно Бьянки - Майокки попросил разрешить производство аппаратов Илизарова в Италии, для чего ему была выдана лицензия на право производства и реализации продукта на территории. 
Но до получения лицензии проф. Б._Майокки организовал патентование аппарата в ведущих странах мира ${ }^{1}$ и разработал товарный знак.

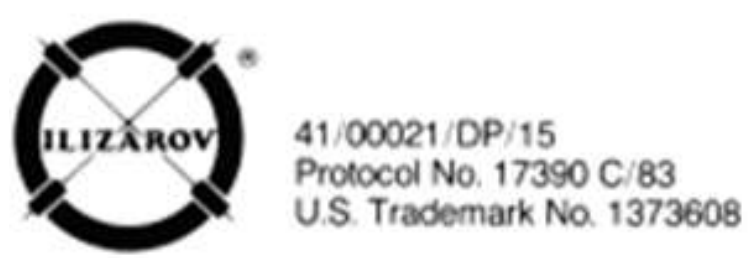

Рис. 7. Товарный знак, предложенный проф. А. Б.-Майокки

При продаже на каждую деталь аппарата должен наноситься товарный знак. Как объяснил нам проф. А. Б Майокки, патенты и товарный знак необходимы для защиты от возможной контрафактной продукции. Мы же ничего этого не знали, так как в Советском союзе патентования новых изделий не производилось, а авторское свидетельство не имело юридической силы. Разработчик новых изделий у нас не имел никакого финансового вознаграждения при промышленном производстве изделия. Всякая новинка считалась государственной собственностью.

Для печати и при оформлении необходимой документации проф. А. Б.- Майокки представил развернутый вид товарного знака.

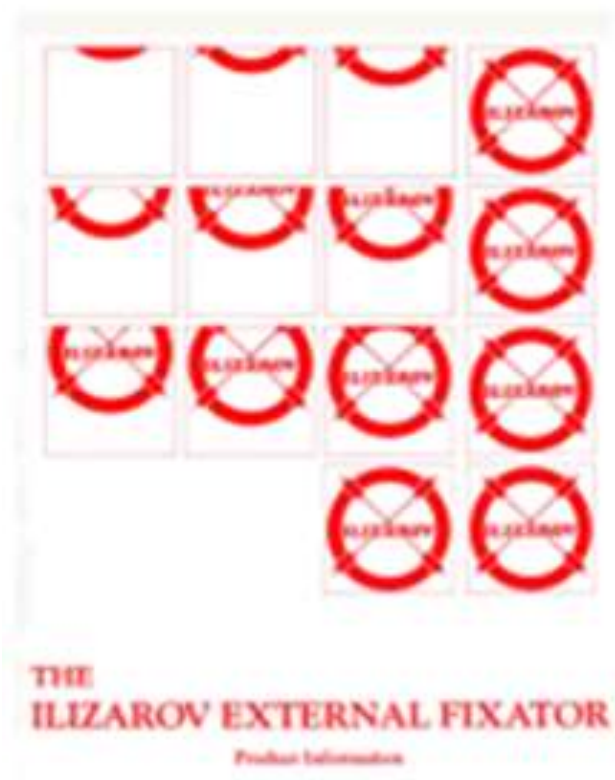

Рис.8. Товарный знак на аппарат Илизарова в развернутом виде.

Он объяснял этот рисунок следующим образом. Вначале информация об аппарате была очень ограниченной. О нем специалисты имели поверхностное впечатление. Это представлено на рисунке сектором кольца.

${ }^{1}$ G.A. Ilizarov: Compression - Dictraction Apparatus USSR: Patent No538710 - A/82; Italy - Patent No 47890 A/82; France - Patent No2587612; Belgium : Patent No 903258; Us: Patent No 4615338; Great Britain Patent No $2180453^{1}$

По мере большей информации и некотором освоении аппарата и метода на рисунке это обозначено половиной кольца. После получения полной информации и хорошем освоении технологии на рисунке это подтверждается полным кольцом.

На одну из конференций в Италию из США прибыли проф. С. Грин и проф.В Франкель. Информация Г.А. Илизарова их очень заинтересовала. Немедленно Г.А. Илизаров был приглашен с лекциями в США. История повторилась так же как в Италии. Американские специалисты были ошеломлены представленными результатами, так как ничего подобного они раньше не видели. Начался американский бум освоения метода Г.А. Илизарова.

В 1989 г организуется АСАМИ США. Но в США ассоциация уже трансформируется в ассоциацию удлинения конечностей и реконструкции. В названии отсутствует имя Илизарова, но он номинирован почетным 
членом АСАМИ США. Но удлинение - это тоже реконструкция. Но так как Г.А. Илизаров не американский ученый, то именем иностранного специалиста не должна называться американская организация. Одним из инициаторов этого названия был проф. Д. Палей. Первым Президентом АСАМИ США был избран проф. Д. Аронсон.

В 1996 г. во время конгресса СИКОТ в г. Амстердаме прошла встреча президентов национальных АСАМИ. Был рассмотрен вопрос о необходимости создания единого международного центра управления деятельностью АСАМИ. Первое организационное заседание по этому вопросу проходило в г. Новый Орлеан в США в 1998 г. Нашим представителем была проф. Г.В. Дьячкова.

На этом заседании был утвержден график проведения конгрессов АСАМИ: каждые три года со сменой континентов: после США - Европа г. Рим, затем Азия - Стамбул, Япония - Киото.

В 2006 г. Конгресс АСАМИ проходил в г. Киото (Япония), на котором проф. В. Шевцов поставил вопрос о введении в состав руководящего органа международной АСАМИ представителя России с правом решающего голоса. До этого представители нашего центра выполняли представительские функции. Меня поддержали проф. Г. Хосни из Египта и проф. Джунджувала из Индии.

И в 2008 г. прошел конгресс АСАМИ в г. Санкт-Петербурге, где проф. В.Шевцов был избран Президентом международной АСАМИ на 2 года.

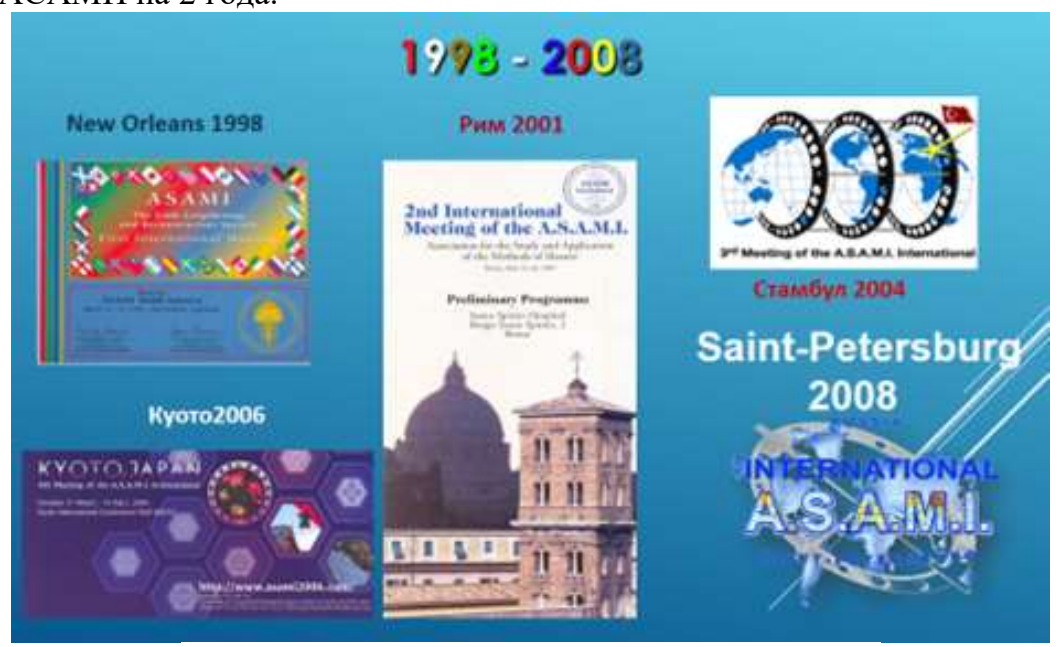

Рис.9. Конгрессы АСАМИ по годам и странам.

Против такого решения активно выступал проф. Д. Палей и ассоциированные с ним представи-тели Бразилии. Но победило большинство в мою пользу.

В 2010 г. я передал скипетр Президента АСАМИ проф. Г. Хосни. В последующие годы начали проводиться региональные конгрессы. Например, Филиппины, Малайзия Сингапур, Таиланд, Индия организовали океаническую группу - ASEAN, свою группу организовали в другой части земного шара Бразилия, Португалия, Кабо-Верде, Ангола, Мозамбик и др.

В целом за время активной работы международной АСАМИ в Российском научном центре «Восстановительная травматология и ортопедия» прошли подготовку по чрескостному остеосинтезу по Илизарову более 4000 специалистов из всех стран мира. Метод широко внедрен в 56 странах мира, в которых организованы АСАМИ. Многие активные пропагандисты и пользователи метода Илизарова стали широко известны в мировой практике. К ним относятся проф. Д. Палей (США), проф. М. Бари (Бангладеш), проф. М. Катаньи (Италия), проф. Г. Хосни (Египет), канд. мед наук Н. Хамди и др.

Я с удовольствием поздравляю проф. М. Бари с организацией Бангладеш - АСАМИ. Он достойный представитель страны в этой организации. Проф. М. Бари отличный оратор, блестящий хирург, большой ученый. Он освоил метод Илизарова, успешно выполняет очень сложные оперативные вмешательства в безнадежных случаях, о чем свидетельствуют опубликованные им научные труды. По его пути пошел и его сын. Я желаю проф. М. Бари дальнейших успехов, не останавливаться на достигнутом, продолжать активную пропаганду метода Илизарова не только в своей, но в других странах.

Таким образом, создание 56 национальных АСАМИ свидетельствует о новизне предложенных Г.А. Илизаровым новых малотравматичных и высокоэффективных технологий удлинения конечностей и регуляции роста, коррекции деформаций, возмещения дефектов длинных костей. Предложенные технологии активно внедряются так как отвечают требованиям современной травматологии и ортопедии, позволяют специалистам оказывать необходимую помощь пациентам при самой тяжелой ортопедической патологии и при тяжелой травме, сопровождающейся шоковым состоянием пострадавших. Высокая эффективность предложенных технологий и их воспроизводимость не только автором, но и другими специалистами, связаны с тем, что 
аппарат Г.А. Илизарова с кольцевыми опорами, характеризуется как биологически ориентированный остеосинтез, представляющий процессуальный метод с постоянной возможностью коррекции. Этот метод учитывает биологическую адаптацию и промежуток времени, необходимый для регенерации костей.

Конфликта интересов не имеется.

Работа выполнена без финансовой поддержки.

Адрес для переписки: 640020 г. Курган, Климова ул, д.41, кв 38 